RU «SMART-обучение» как новая образовательная модель: отношение педагогов и обучающихся

\begin{abstract}
Черных А. А., Кролевецкая Е. Н.
Аннотащия. Цель исследования - изучение отношения педагогов и обучающихся к новой образовательной модели SMART-обучения. В статье акцентируется внимание на особенностях современного образования в условиях внедрения SMART-обучения. Исследование позволило оценить, насколько педагоги и обучающиеся знакомы с концепцией умного образования, выявить особенности внедрения SMART-обучения в образовательных организациях Белгородской области. Научная новизна исследования заключается в раскрытии сущности понятия «SMART-обучение» как новой образовательной модели, которая в настоящее время активно внедряется в образовательных организациях разного уровня. В результате представлены данные, которые свидетельствуют, с одной стороны, о признании педагогами высокой важности и позитивного влияния SMART-среды на возможности развития образования в целом, а с другой стороны, об отсутствии активной субъектной позиции педагогов в вопросе внедрения SMART-технологий в образовательный процесс.
\end{abstract}

\title{
SMART Learning as New Educational Model through the Eyes of Teachers and Students
}

\author{
Chernykh A. A., Krolevetskaya E. N.
}

\begin{abstract}
The paper analyzes teachers' and students' attitude to a newly accepted SMART learning model, reveals peculiarities of SMART education. Relying on the conducted analysis, the authors identify how well teachers and students are familiar with SMART learning conception, discover specificity of introducing SMART technologies in educational institutions of Belgorod region. Scientific originality of the study involves revealing the essence of SMART learning as a new educational model recently implemented in educational institutions of different levels. The conducted research allows drawing the following conclusions: teachers accept importance of SMART technologies and recognize the potential of SMART learning environment in improving the educational process quality, however, they failed to develop a subjective position on the problem of SMART technologies introduction.
\end{abstract}

\section{Введение}

Tермин "SMART" (от англ. «умный») в последнее время стал невероятно популярным, модным словом, используемым в различных контекстах, от еды до научных систем. Изначально понятие "SMART" возникло, прежде всего, в технологическом аспекте. Ярлык “SMART” используется, когда что-то было технологически усовершенствовано, или продукт был адаптирован к потребностям человека с помощью какого-либо технологического решения, или даже когда новая версия продукта разрабатывается с некоторыми (незначительными) технологическими усовершенствованиями.

В педагогическом лексиконе в настоящее время закрепились термины «SMART-образование», «SMARTобучение», «SMART-технологии», «SMART-среда». Активно развивается новая образовательная парадигма SMART-образование, которая подразумевает становление новых ориентиров и моделей образования в информационном обществе. Создание модели SMART-обучения предполагает необходимость внедрения в образовательное пространство современных высокотехнологичных, интеллектуальных, комфортных систем для обучающихся и педагогов. SMART-обучение - это «УMHOE обучение», реализуемое в интерактивном пространстве с использованием открытых ресурсов всего мирового сообщества. Такая модель соответствует требованиям инновационности, гибкости к происходящим в обществе изменениям, адаптивности к растущим запросам обучающихся. 
Изучение отношения педагогов и обучающихся к новой образовательной модели SMART-обучения представляется нам актуальной педагогической проблемой, связанной с ценностным переосмыслением и пониманием инновационных методов и технологий взаимодействия в информационно-образовательной среде.

Для достижения указанной цели необходимо решить следующие задачи исследования:

- изучить сущность понятия «SMART-обучение» в контексте новой образовательной парадигмы;

- выявить отношение педагогического сообщества и обучающихся к образовательной модели «SMARTобучение».

В ходе исследования использовались следующие методы: теоретические (анализ и обобщение нормативной документации и научной литературы по проблеме внедрения SMART-обучения; методы качественного анализа документов и продуктов профессиональной деятельности педагогов, моделирование); эмпирические (наблюдение, анкетирование); методы математической обработки результатов исследования.

Теоретической базой исследования послужили работы таких отечественных авторов, как Б. Л. Агранович [1], А. Г. Асмолов [2], Л. М. Митина [3], П. Д. Рабинович, К. Е. Заведенский, М. Э. Кушнир, Ю. Е. Храмов, А. Р. МеликПарсаданов [4], О. Ю. Рыбичева [5], В. П. Тихомиров [6] и зарубежных авторов, таких как К. Глассвелл, К. Дэвис, П. Сингх и С. Макнотон [7], Д. Гвак [8], Дж. Дж. Хван [9], С. Джанг [10], Т. Ким, Дж. У. Чу, Б. Г. Ли [12], Дж. Ли и др. [13], А. Миддлтон [14], К. Мураи, Ю. Хаяси, Л. К. Стоун и С. Инокучи [15], К. Скотт и Р. Бенламри [16], Е. Р. Сайкс [17], 3. Т. Чжу и Б. Хе [18], 3. Т. Чжу и Д. М. Шен [19], в публикациях которых отражены основные характеристики умного обучения.

Практическая значимость работы состоит в возможности использования полученных результатов в педагогической практике для развития современного образовательного процесса в условиях внедрения SMART-обучения.

\section{Характеристика SMART-обучения как новой образовательной модели}

SMART-обучение направлено на обеспечение целостного обучения школьников и студентов с использованием современных технологий, чтобы полностью подготовить их к быстро меняющемуся миру, где способность к адаптации имеет решающее значение.

B качестве новой образовательной модели «SMART-обучение» или «УМHOE обучение» основывается на умных устройствах и умных технологиях [14]. Обучение с использованием технологий (TEL - Transforming and Educating for Life) обеспечивает гибкость в процессе получения новой информации. Эти технологии представлены средствами массовой информации или инструментами для доступа к обучающему контенту [8], запросам, коммуникациям и сотрудничеству, построению [11], выражению [19] и оценке деятельности [16] в TEL.

Пока нет четкого и единого определения «умного обучения». Многопрофильные исследователи и специалисты в области образования постоянно обсуждают концепцию SMART-обучения. Тем не менее некоторые важные компоненты нашли отражение в научной литературе.

Дж. Г. Хван, К. Скотт и Р. Бенламри считают, что SMART-обучение - это повсеместное обучение с учетом контекста [9; 16]. Д. Гвак охарактеризовал концепцию SMART-обучения следующим образом: во-первых, оно ориентировано на учащихся и образовательный контент больше, чем на устройства; во-вторых, это эффективное, интеллектуальное, индивидуальное обучение, основанное на передовой ИТ-инфраструктуре. Технология играет важную роль в поддержке «умного обучения», но основное внимание следует уделять не только использованию интеллектуальных устройств [8]. Т. Ким, Дж. У. Чу, Б. Г. Ли считают, что интеллектуальное обучение, сочетающее в себе преимущества социального обучения и повсеместного обучения, представляет собой образовательную парадигму, ориентированную на учащегося и образование, а не только на использование устройств [12, p. 173]. Дж. Ли предложил, чтобы функции интеллектуального обучения включали формальное и неформальное обучение, социальное и совместное обучение, персонализированное и ситуативное обучение, а также ориентацию на приложения и контент [13, p. 1084].

SMART-обучение основано на пяти элементах, вытекающих из аббревиатуры SMART: 1) “Self-directed” самоуправляемый, 2) “Motivated” - мотивированный, 3) “Adapted” - адаптированный, 4) “Resource enriched” обогащенный ресурсами и 5) “Теchnology-embedded” - встроенный в технологии [11]. С. Джанг [10, p. 75] характеризует эти элементы следующим образом:

1) «самоуправляемый» характеризует изменение ролей учащихся как получателей знаний и превращение учителей из распространителей знаний в помощников по обучению (наставников). Для этого также внедряются онлайн-оценки, оценки успеваемости и система самостоятельного обучения;

2) «мотивированный» подчеркивает, каким образом SMART-обучение побуждает учащихся проявлять интерес к обучению. SMART-обучение уделяет особое внимание методам преподавания и обучения, которые способствуют творческому решению проблем и индивидуальной оценке, ориентированной на процесс. Учебный опыт обучающихся трансформируется от теоретического учебного опыта к практическому;

3) «адаптированный» означает продолжение образования через индивидуализированную образовательную систему и индивидуальную систему преподавания и обучения. SMART-обучение повышает гибкость об будущими карьерными устремлениями. Это также помогает образовательным учреждениям превратиться из места передачи знаний в место, которое поддерживает индивидуальное обучение в соответствии с уровнями и способностями учащихся; 
4) «обогащенный ресурсами» описывает поддержку различных материалов для преподавания и обучения. SMART-обучение предоставляет бесплатный доступ к обширному контенту, разработанному государственными и частными учреждениями и отдельными лицами в сфере образования, через облачную обучающую платформу, расширяет совместное использование внутренних и зарубежных учебных ресурсов и способствует совместному обучению с помощью платформ трансляции контента;

5) «встроенный в технологии» показывает использование новейших информационных и коммуникационных технологий. SMART-обучение позволяет учащимся учиться в любое время и в любом месте с помощью информационных технологий. Создается образовательная среда, которая поощряет обучение, ориентированное на учащихся, учащимся предоставляются разнообразные методы обучения, адаптированные к выбранным ими областям интересов.

Умное образование считается наиболее прогрессивным этапом изменения образования с помощью новых ИКТ. Как постоянно подчеркивают исследователи, умное образование, несомненно, является важной перспективой модернизации образовательных систем, направленной на приведение образования в соответствие с требованиями современного стремительного мира и на создание такой системы образования, которая могла бы пережить продолжающуюся технологическую революцию. Многие исследования подтверждают эффективность и привлекательность SMART-обучения [7; 15].

Анализ соответствующей литературы приводит к выявлению трех основных позиций, поддерживающих интеллектуальное образование: (1) мобильные технологии, (2) цифровые учебники и (3) облачные технологии.

1. Мобильные технологии - это ключевая технология SMART-обучения, поскольку она представляет собой стратегию обучения повсюду в соответствии с индивидуальными предпочтениями учащихся. Используя смартфоны, планшеты и другие портативные устройства, учащиеся могут выполнять учебные задания в любом месте, даже за пределами традиционного школьного здания. Исследования, проведенные Е. Р. Сайксом [17], показывают, что использование мобильных устройств в образовании повышает эффективность обучения.

2. Согласно С. Джангу, цифровой учебник - это «ориентированный на будущее», технологически усовершенствованный и более привлекательный учебник [10, p. 76]. Помимо функций традиционного учебника, цифровая версия также выступает в качестве записной книжки для самостоятельного изучения, рабочей тетради и словаря. Он также содержит различные инновационные учебные пособия. Кроме того, в цифровом учебнике используются передовые технологические элементы, такие как видео, анимация, виртуальная реальность или гиперссылки. Цифровой учебник также интерактивен и за счет этого адаптируется к способностям, навыкам и уровню каждого ученика. Цифровой учебник функционирует в среде так называемого N-экрана (иногда называемого трехэкранным, применительно к трем основным контекстам использования: Интернет, мобильный телефон, ТВ), поэтому его можно использовать на любом экране - компьютера, планшета, смартфона, телевизора.

3. Облачные технологии - это широко используемый термин, который включает в себя ряд двусмысленностей в отношении его определения. В своей наиболее простой форме облачные технологии - это стратегия передачи различных типов программ или материалов с дисков персонального компьютера в сеть (облако), чтобы их можно было использовать в любом месте и на любом устройстве [11]. С точки зрения образования облачные технологии, попросту говоря, представляют собой технологическое облако, в котором хранятся учебные материалы в различных форматах (текст, фильм, звук и т.д.). В этом облаке устанавливаются приложения и образовательные программы, а также средства связи, используемые различными заинтересованными сторонами в сфере образования (учащиеся, учителя, родители, администрации образовательных учреждений и т.д.). С технологической точки зрения это облако доступно на всех устройствах (смартфонах, компьютеpax, телевизорах и т.д.), что делает процесс обучения доступным везде и в любое время.

A. Миддлтон [14] также рассматривает аспекты SMART-обучения, ориентированные на учащихся, и преимущества использования умных технологий. Современные технологии побуждают учащихся участвовать в обучении и повышать свою независимость более открытыми, связанными и расширенными способами за счет более богатого личного контекста.

B. П. Тихомиров говорит о SMART-обучении как о новой концепции, которая предполагает комплексную модернизацию всех образовательных процессов, а также методов и технологий, используемых в этих процесcax. Концепция SMART в образовательном разрезе влечет за собой появление таких технологий, как умная доска, умные экраны, доступ в Интернет из любой точки. Каждая из этих технологий позволяет по-новому построить процесс разработки контента, его доставки и актуализации [6, с. 24].

Б. Л. Агранович утверждает, что каждая эпоха создавала свой вид образования на основе соответствующего социально-экономического и культурологического базиса общества [1]. Традиционная классно-урочная система образования Я. Коменского, созданная в XVII веке, изжила себя в условиях формирующегося постиндустриального общества, так как построена на других социально-экономических и культурологических основаниях. Автор говорит о необходимости создания системы образования постиндустриального общества, социально-экономические и культурологические основания которого принципиально ставят задачу перехода от эпохи образования в новую эпоху SMART-самообразования, для которого созданы в пятом технологическом укладе все необходимые предпосылки.

А. Г. Асмолов, П. Д. Рабинович являются авторами концепции «Техносфера образовательного учреждения», в основе которой лежат идеи открытого вариативного образовательного пространства. Кроме того, А. Г. Асмолов подчеркивает важность системно-деятельностного подхода в образовании, основанного на теоретических 
положениях концепции Л. С. Выготского, А. Н. Леонтьева и др., ориентированного на практическую учебнопознавательную деятельность детей, формирование подрастающего поколения, мотивированного на приобретение и развитие современных компетентностей [2].

O. Ю. Рыбичева отмечает, что более широкое понятие SMART-образования характеризуется отечественными и зарубежными учеными как образовательная парадигма, образовательная среда, образовательная система, образовательная сеть, образовательный процесс. В основе определения SMART-образования как парадигмы лежит выделение его в качестве новой концептуальной идеи развития образования, базирующейся на реализации адаптивного учебного процесса и использовании интеллектуальных информационных технологий. Рассмотрение его с позиции образовательной среды ведет к выделению создаваемой интеллектуальной среды как одного из основных элементов SMART-образования, наряду со SMART-обучающимися и SMARTпедагогикой. Сущность системного подхода к определению понятия «SMART-образование» заключается в видении его как системы, обеспечивающей приобретение гражданами необходимых знаний, навыков, умений и компетенций с помощью Интернета, взаимодействие с окружающей средой и процессом обучения и воспитания. Особенностью сетевого подхода является рассмотрение SMART Education как образования, организованного в Интернете общими усилиями учебных заведений и профессорско-преподавательского состава на базе общих стандартов, соглашений и технологий. Процессуальный подход базируется на выделении SMARTобразования как процесса получения знаний на основе различных технических средств [5, с. 80].

Мы разделяем точку зрения 3. Т. Чжу и Б. Хе, которые заявили, что «сущность умного обучения заключается в создании интеллектуальной среды с использованием умных технологий, которая способствует модернизации педагогической деятельности, чтобы предоставлять персонализированные услуги обучения и расширять возможности учащихся и педагогов и таким образом развивать таланты, которые имеют большую ценность, способствуют ориентации в современном мире, более высокому качеству мышления и более сильным поведенческим способностям» $[18$, p. 6]. Рамки исследования на основе этого определения отражены на Рисунке 1.

B данной структуре отражены три основных элемента SMART- обучения: SMART-среда, SMART-педагогика и SMART-ученик. SMART-обучение подчеркивает идеологию стремления к лучшему образованию и поэтому логично трансформируется в SMART-образование, которое удовлетворяет потребности в умной педагогике как методологической проблеме и умной учебной среде как технологической проблеме. SMART-среда может быть подвержена значительному влиянию SMART-педагогики. SMART-педагогика и SMART-среда способствуют развитию SMART-учеников.

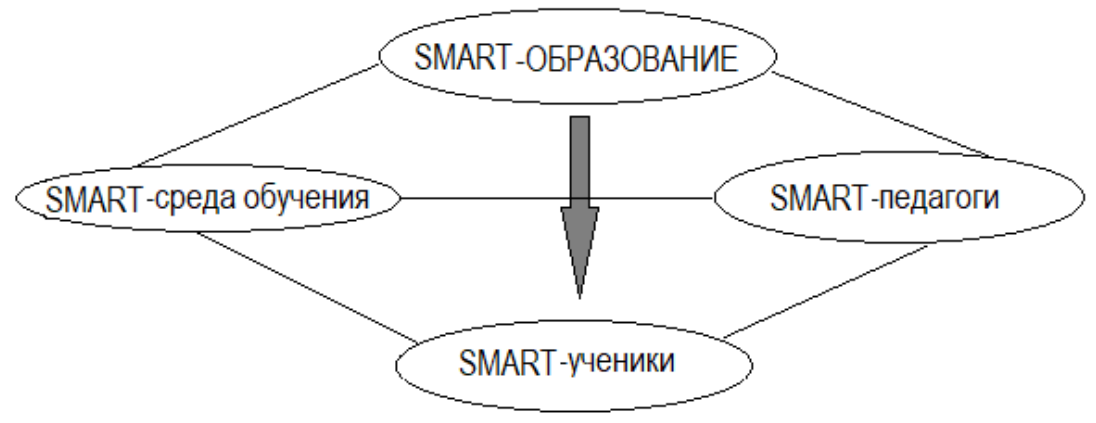

Рисунок 1. Структура SMART-образования

Таким образом, мы можем утверждать, что существуют различные варианты трактовок понятия «SMARTобучение», однако у них много общего: SMART-обучение определяется как самостоятельная, мотивированная, адаптивная модель образовательного процесса, обогащенная информационными ресурсами и встроенная в современные образовательные технологии. Кроме того, SMART-обучение предлагает смену парадигмы в способах доступа обучающихся к образованию. Оно направлено на обеспечение целостного образовательного процесса с использованием современных умных технологий, чтобы полностью подготовить обучающихся и педагогический коллектив к быстро меняющемуся миру, где способность к адаптации имеет решающее значение.

\section{Исследование отношения педагогов и обучающихся к внедрению «умного обучения»}

На сегодняшний день проект SMART-обучения еще не сформулировал точных методических образовательных решений, которые бы подробно описывали, как работать со школьниками и студентами в SMARTсреде образовательной организации с использованием SMART-технологий. Педагогическим работникам приходится самостоятельно адаптироваться к современным образовательным инновациям, учиться трансформировать свои традиционные методы обучения в обучение с использованием информационных технологий.

B этом контексте представляется целесообразным изучить, как педагогические работники оценивают SMART-обучение, учитывая их ведущую роль в будущем внедрении таких высокотехнологичных решений в образовании, а также выяснить у обучающихся их позицию относительно становления новой образовательной парадигмы «SMART-образование». 
Для этого нами было проведено исследование, позволяющее оценить, насколько педагоги и обучающиеся знакомы с концепцией умного образования, проводится ли работа по внедрению SMART-обучения в образовательных организациях; определить отношение педагогов и обучающихся к внедрению SMART-образования и доступность инновационной образовательной среды.

Опрос проводился в удаленном режиме с помощью Google-формы, которая содержала закрытые и открытые вопросы. В нем приняли участие учителя школ, педагоги образовательных организаций среднего профессионального образования и преподаватели вузов, ученики и студенты Белгородской области. Всего было опрошено 186 человек: 44\% опрошенных пришлось на учителей школ, 15\% - на преподавателей вузов и колледжей, 37\% опрошенных - на студентов и 3\% - на школьников. Возрастная категория участников опроса: $42 \%$ - от 30 до 45 лет, 40\% - от 45 до 55 лет, 10\% - более 55 лет и 8\% - молодые люди от 18 до 30 лет, школьники в возрасте от 12 до 17 лет.

Результаты исследования свидетельствуют о том, что 65\% респондентов знакомы с понятием «SMARTобразование», однако 16\% опрошенных не имеют общего представления о данном понятии, а 19\% затруднились дать ответ на поставленный вопрос.

Что касается сущности понятия «SMART-образование», большая часть опрошенных (43\%) считает, что «SMART-образование» - это образовательная система, однако $20 \%$ респондентов больше склоняются к средовому или парадигмальному определению данного понятия, 12\% утверждают, что SMART-образование это управляемый процесс, и лишь 5\% считают, что это учебная сеть (Рисунок 2).

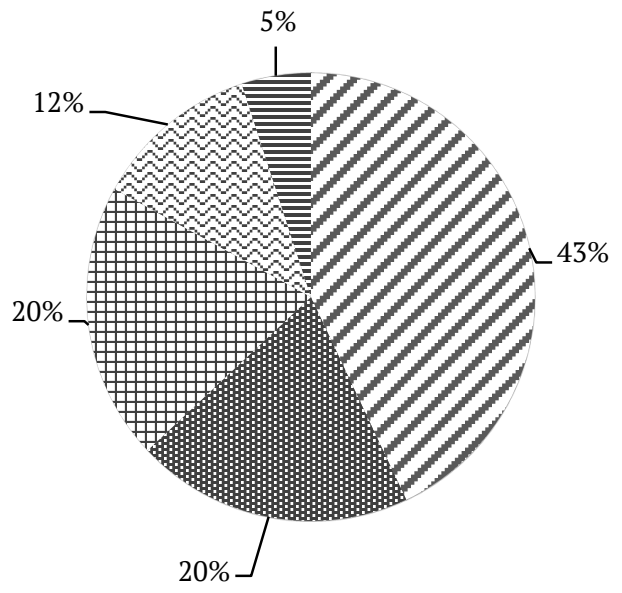

$$
\text { ヶ образовательная система }
$$

э⿱ интеллектуальная среда

+ образовательная парадигма

управляемый процесс

三учебная сеть

Рисунок 2. Распределение ответов на вопрос о сущности понятия «SMART-образование»

Относительно определения структуры понятия «SMART-обучение» мы выяснили, что большая часть опрошенных (75\%) считает, что SMART-обучение включает в себя формальное и неформальное обучение, 20\% полагает, что SMART-обучение заключается только в неформальном обучении, а 5\% - только в формальном.

Многие современные педагоги не разделяют понятия «SMART-обучение» и «Электронное обучение (e-learning)», полагая, что данные термины имеют тождественное определение. Анализ результатов показал, что 36\% ошибочно считают, что «SMART-образование» и «Электронное обучение (e-learning)» имеют одно и то же значение, $64 \%$ педагогов считают, что эти понятия различны.

Вместе с тем 49\% опрошенных считают, что SMART-обучение - это определенная модель обучения, а $51 \%$ вспомогательное средство.

Следующий блок вопросов был задан педагогам, ученикам и студентам для того, чтобы понять, насколько распространено SMART-образование в Белгородской области. Большая часть опрошенных респондентов подтвердила использование в образовательных организациях Белгородской области элементов SMARTобразования (52\%), 42\% затруднились ответить на поставленный вопрос, а 6\% утверждают, что в их образовательных организациях не используются элементы SMART-образования.

Кроме того, участникам опроса было предложено конкретизировать элементы, которыми представлено SMART-образование в образовательных организациях. Мы получили следующие ответы: современное образовательное пространство и техническое обеспечение отметили 59\% опрошенных, новые методы и подходы в образовании - 21\%, а 20\%, к сожалению, затруднились ответить на данный вопрос. Вместе с тем лишь $31 \%$ респондентов отметили, что являются активными участниками SMART-обучения, 39\% подчеркнули скептическое отношение к процессу внедрения SMART-обучения, 30\% затруднились ответить.

B качестве перспектив внедрения модели SMART-обучения многие участники опроса отметили высокий уровень развития образования в России, обновление всего образовательного процесса страны в целом, осуществление прорывного научно-технического и социально-экономического развития России и возможности инновационного образования, которое позволит наладить дальнейшее сотрудничество образовательных организаций с мировыми образовательными платформами. Однако были и те, кто воздержался от ответа или выразил резко негативное отношение к новой образовательной модели. Мы получили следующее ответы: 
«SMART-обучение, как и всё, - забуксует», «SMART-обучение не найдет поддержки», «В России достаточно сложностей с перспективами в образовании, SMART-образование не будет развито», «У нас всегда есть перспективы внедрения нового, обидно, что не сохраняем самое лучшее из своих технологий обучения».

Отметим, что скептическое отношение к внедрению SMART-обучения как новой образовательной модели пришлось в основном на учителей школ в возрасте от 45 лет и старше. Можно предположить, что причина такого негативного мнения заключается в страхе перед новыми технологиями, применение которых может нарушить привычный образовательный процесс, и недостаточной осведомленности о положительном влиянии инновационных технологий на качество обучения.

Большее количество положительных оценок было зафиксировано в ответах учеников, студентов и преподавателей в возрасте до 30 лет. Это объясняется тем, что современному поколению молодых людей всегда легче адаптироваться к быстроразвивающемуся технологическому процессу, а следовательно, и в перспективе внедрения SMART-образования они видят больше преимуществ, чем недостатков.

По мнению большинства учителей и преподавателей (72\%), SMART-технологии и SMART-среда позитивно влияют на возможности исследовательской деятельности, как собственной, так и со школьниками и студентами, так как предоставляют широкие возможности для развития исследовательской компетенции, повышают уровень мотивации к исследованию, способствуют доступности использования современных форм и методов в обучении. Однако $28 \%$ опрошенных утверждают, что затрудняются отметить положительные стороны влияния SMART-среды на образовательный процесс, так как в своей профессиональной деятельности не используют элементы SMART-образования.

Проанализировав полученные результаты опроса, мы пришли к выводу, что в Белгородской области проходит процесс внедрения модели SMART-обучения, большая часть респондентов знакома с понятиями «SMARTобразование», «SMART-обучение», понимает характеристики и основные отличия данной модели обучения от других. 53\% опрошенных утверждают, что в их образовательных организациях используются элементы SMART-образования, которые представлены интерактивной образовательной средой и современным техническим обеспечением, новыми методами, технологиями и подходами в образовании. Хотелось бы отметить, что, не смотря на осведомленность в вопросе SMART-образования со стороны опрошенных, лишь $31 \%$ респондентов могут отнести себя к активным участникам SMART-образования.

Таким образом, отмечая высокую важность и позитивное влияние SMART-среды на возможности развития образования в целом, педагоги вместе с тем в большинстве не являются активными субъектами внедрения SMART-технологий в образовательный процесс. Треть опрошенных педагогов скептически относится к внедрению данной инновации, предпочитают в своей работе применять традиционные методы и технологии. Данное обстоятельство обуславливает необходимость усиления внимания к ценностно-мотивационной составляющей профессиональной деятельности педагога в условиях внедрения SMART-образования.

\section{Заключение}

Проведенный теоретический анализ проблемы исследования показал, что SMART-обучение - это новая модель в глобальном образовании, способная повысить качество образования, ориентированная на контекстное, персонализированное и непрерывное обучение, которое способствует развитию интеллекта обучающегося и развивает способность решать проблемы в современной «умной среде».

Эмпирическое исследование показало, что в образовательных организациях Белгородской области активно внедряется модель SMART-обучения. Вместе с тем лишь третья часть респондентов отнесла себя к ее активным участникам. Педагоги школ, колледжей и вузов отмечают уникальные возможности SMART-среды в осуществлении учебной и исследовательской деятельности, но в практической деятельности предпочитают применять традиционные педагогические методы и технологии.

Перспективы дальнейшего исследования проблемы мы видим в более детальном изучении ценностномотивационной составляющей профессиональной деятельности педагога в условиях внедрения SMARTобразования.

\section{Источники | References}

1. Агранович Б. Л. Вызовы и решения: подготовка магистров для постиндустриальной экономики // Инженерное образование. 2011. № 8. С. 56-61.

2. Асмолов А. Г. Психология личности: культурно-историческое понимание развития человека. М.: Смысл, 2007. $528 \mathrm{c}$.

3. Митина Л. М. Психология профессионального развития учителя. М.: Флинта; Моск. психол.-соц. ин-т, 2008. 200 c.

4. Рабинович П. Д., Заведенский К. Е., Кушнир М. Э., Храмов Ю. Е., Мелик-Парсаданов А. Р. Цифровая трансформация образования: от изменения средств к развитию деятельности // Информатика и образование. 2020. № 5 (314). С. 4-14.

5. Рыбичева О. Ю. Перспективы внедрения смарт-технологий в образовательный процесс // Вестник Вятского государственного университета. 2019. № 4 (134). С. 76-84. 
6. Тихомиров В. П. Мир на пути Smart education. Новые возможности для развития // Открытое образование. 2011. № 3. C. 22-28.

7. Glasswell K., Davis K., Singh P., McNaughton S. Literacy lessons for Logan learners: A smart education partnerships project // Curriculum Leadership. 2010. Vol. 31. № 8. P. 1-4.

8. Gwak D. The meaning and predict of Smart Learning. Smart Learning Korea Proceeding. Korean e-Learning Industry Association, 2010. $112 \mathrm{p}$.

9. Hwang G. J. Definition, framework and research issues of smart learning environments - a context-aware ubiquitous learning perspective // Smart Learning Environments. 2014. Vol. 1. № 1. P. 1-14.

10. Jang S. Study on Service Models of Digital Textbooks in Cloud Computing Environment for SMART Education // International Journal of U- \& E-Service, Science \& Technology. 2014. Vol. 7. № 1. P. 73-82.

11. Kim B. H., Oh S. Y. A Study on the SMART Education System Based on Cloud and N-screen // Journal of the Korea Academia-Industrial Cooperation Society. 2014. Vol. 15. № 1. P. 137-143.

12. Kim T., Cho J. Y., Lee B. G. Evolution to smart learning in public education: A case study of Korean public education // Open and Social Technologies for Networked Learning. Berlin - Heidelberg: Springer, 2013. P. 170-178.

13. Lee J., Zo H., Lee H. Smart learning adoption in employees and HRD managers // British Journal of Educational Technology. 2014. Vol. 45. № 6. P. 1082-1096.

14. Middleton A. Smart learning: Teaching and learning with smartphones and tablets in post compulsory education [Электронный ресурс]. URL: https://www.academia.edu/12512765/Smart_learning_teaching_and_learning_with_ smartphones_and_tablets_in_post_compulsory_education (дата обращения: 21.08.2021).

15. Murai K., Hayashi Y., Stone L. C., Inokuchi S. Basic Evaluation of Performance of Bridge Resource Teams Involved in On-Board Smart Education: Lookout Pattern // Review of the Faculty of Maritime Sciences, Kobe University. 2006. Vol. 3. P. 77-83.

16. Scott K., Benlamri R. Context-aware services for smart learning spaces // IEEE Transactions on Learning Technologies. 2010. Vol. 3. Iss. 3. P. 214-227.

17. Sykes E. R. New Methods of Mobile Computing: From Smartphones to Smart Education // TechTrends: Linking Research and Practice to Improve Learning. 2014. Vol. 58. № 3. P. 26-37.

18. Zhu Z. T., He B. Smart Education: New frontier of educational informatization // E-education Research. 2012. № 12. P. 1-13.

19. Zhu Z. T., Shen D. M. Learning analytics: The science power of smart education // E-education Research. 2013. № 5. P. 5-12.

\section{Информация об авторах | Author information}

RU Черных Арина Андреевна

Кролевецкая Елена Николаевна ${ }^{2}$, к. пед. н., доц.

1,2 Белгородский государственный национальный исследовательский университет

EN Chernykh Arina Andreevna

Krolevetskaya Elena Nikolaevna ${ }^{2}, \mathrm{PhD}$

1,2 Belgorod National Research University

1,2 krolevetskaya@bsu.edu.ru

\section{Информация о статье | About this article}

Дата поступления рукописи (received): 17.06.2021; опубликовано (published): 15.09.2021.

Ключевые слова (keywords): SMART-обучение; образовательная модель; педагог; SMART-технологии; субъектная позиция; SMART learning; educational model; teacher; SMART technologies; subjective position. 